\title{
Belgeo
}

Revue belge de géographie

\section{De Waele J.M. (éd.), Les clivages politiques en Europe centrale et orientale}

Bruxelles, Editions de l'Université de Bruxelles, 2004, 288 p.

\section{Christian Vandermotten}

\section{OpenEdition}

\section{Journals}

Édition électronique

URL : http://journals.openedition.org/belgeo/12362

DOI : $10.4000 /$ belgeo.12362

ISSN : 2294-9135

Éditeur :

National Committee of Geography of Belgium, Société Royale Belge de Géographie

Édition imprimée

Date de publication : 30 septembre 2005

Pagination : 412-414

ISSN : 1377-2368

Référence électronique

Christian Vandermotten, «De Waele J.M. (éd.), Les clivages politiques en Europe centrale et orientale », Belgeo [En ligne], 3 | 2005, mis en ligne le 28 octobre 2013, consulté le 05 février 2021. URL : http:// journals.openedition.org/belgeo/12362 ; DOI : https://doi.org/10.4000/belgeo.12362

Ce document a été généré automatiquement le 5 février 2021

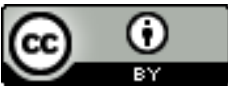

Belgeo est mis à disposition selon les termes de la licence Creative Commons Attribution 4.0 International. 


\title{
De Waele J.M. (éd.), Les clivages politiques en Europe centrale et orientale
}

Bruxelles, Editions de l'Université de Bruxelles, 2004, 288 p.

\author{
Christian Vandermotten
}

\section{RÉFÉRENCE}

DE WAELE J.M. (éd.), Les clivages politiques en Europe centrale et orientale, Bruxelles, Editions de l'Université de Bruxelles, 288 p.

1 Voici un nouvel ouvrage fort intéressant dans la déjà riche collection de sociologie politique des Editions de l'Université de Bruxelles. Il est évidemment impossible de résumer, ne fut-ce que succinctement, un tel livre. Il rassemble quatorze articles d'auteurs différents et traitant spécifiquement de la Pologne, de la République tchèque, de la Lettonie, de la Lituanie, de la Roumanie et de la Bulgarie. Nous nous attacherons donc plutôt dans ce compte rendu à quelques considérations générales sur la formation des clivages en Europe centrale et orientale et sur la validité de l'application des théories de Rokkan à cette partie de l'Europe. Ces thèmes généraux, essentiels pour la construction de géographies électorales comparées, sont développés dans l'introduction et les deux premiers articles par Jean-Michel De Waele et Antoine Roger, ainsi que par Daniel-Louis Seiler, dont on connaît la fidélité « filiale » à Rokkan. On les retrouve aussi en filigrane dans d'autres contributions, même si une vue d'ensemble des systèmes de clivage applicable à tous les pays de l'Europe centre-orientale reste sans doute encore à développer.

2 On sait la complexité et l'instabilité des paysages politiques dans les nouvelles démocraties électorales du centre et de l'est européens. Les classifications partisanes de l'Europe occidentale sont inadaptées et les fréquentes filiations entre l'ancienne nomenklatura (et en particulier le « communisme patrimonial») et les nouvelles élites, 
converties à la propriété privée et souvent au capitalisme sauvage, rendent ambiguës bien des étiquettes, en particulier celles qui renvoient au socialisme ou à la socialdémocratie. Si les deux premiers auteurs soulignent avec raison l'insuffisance des études sur la formation historique des grands clivages politiques face à la multiplication de celles consacrées à l'organisation des appareils dirigeants et des réseaux de militants, on peut toutefois regretter que ni l'article de De Waele et Roger, ni celui de Seiler, n'examinent avec suffisamment d'attention la question de la transition parmi la nomenklatura et son poids dans la formation du système partisan (cf. en revanche l'article de D. Barbu sur la Roumanie). Si on peut suivre ces auteurs sur la reconnaissance de l'importance des modèles génétiques pour expliquer les formes de la reconstitution des systèmes partisans, Seiler me semble toutefois surestimer les parallélismes avec les thèses de Rokkan («l'écueil systématique de l'étirement conceptuel ", comme le dit bien S. Soare dans son article sur la Roumanie). Bien des aspects de la mise en place de ces systèmes partisans nous apparaissent, tout comme à plusieurs auteurs des monographies, bien moins rokkaniens que ne le suggère Seiler. Il nous semble aussi que Seiler, à trop vouloir rester en accord avec la théorie du " père fondateur » des clivages, c'est-à-dire à se placer exclusivement sur le plan structurel des temps longs (dont nous sommes par ailleurs parmi les premiers à souligner l'importance), se coupe toutefois ici d'une réalité objective politique mouvante, qui a à la fois des bases sociales et économiques objectives et est en même temps influencée par des positions certes opportunistes, mais qui peuvent devenir peu à peu des bases structurelles: la scolastique partisane crée à son tour des réalités objectives. Les clivages en Europe centrale et orientale nous apparaissent aussi devoir en partie du moins s'inscrire à terme dans les logiques des systèmes partisans de l'Europe occidentale, parce qu'il nous semble que la soumission de ces pays à l'Europe occidentale est plus mue par des objectifs économiques de celle-ci que ne le disent De Waele et Roger et qu'il ne faut pas sous-estimer l'impact d'alliances partisanes internationales, fussent-elles mêmes mues au départ par des considérations purement opportunistes. Nous sommes en revanche pleinement en accord avec De Waele et Roger quand ils avancent que les clivages actuels en Europe centrale et orientale sont fondés sur les réponses que les partis de ces pays donnent aux impositions de l'Union européenne dans le cadre de la formation d'une nouvelle économie dépendante. Ils distinguent trois familles de clivages :

- un clivage directionnel - la réponse aux exigences économiques des puissances extérieures dominantes - maximaliste quand il y a soumission à ces exigences - dans l'espoir de se moderniser et pour assurer une émancipation future? ou plutôt par intérêt personnel des groupes politiques dominants ? - ou minimaliste, quand les réformes sont limitées à ce qui est nécessaire pour obtenir l'aval européen, tout en maintenant un contrôle de l'Etat sur l'économie et un volant de garanties sociales ;

- un clivage référentiel, autoritaire vs. démocratique, fondé sur la réponse identitaire donnée ou non au statut imposé par les puissances extérieures dominantes ;

- un clivage catégoriel, fondé sur les réponses et revendications spécifiques de catégories victimes du creusement des écarts sociaux (clivages ethniques, urbain-rural, etc.).

3 Les monographies nationales qui suivent ces chapitres initiaux confirment à notre sens que les positions de Seiler doivent à tout le moins être nuancées et que, en particulier, le clivage gauche-droite, dont Seiler refuse la pertinence même en Europe occidentale, s'opposant en cela à Maurice Duverger, n'est pas non plus dépourvu d'intérêt dans l'analyse des systèmes partisans centre- et est-européens. Mais ce clivage gauche-droite 
doit être manié avec beaucoup de nuances et en référence aux cadres nationaux spécifiques, comme le montrent par exemple les contributions de T. Zarycki sur la Pologne, de M. Perottino sur la République tchèque ou de $\mathrm{A}$. Ramonaitè sur la Lituanie.

4 Notons aussi l'intéressante contribution transnationale de A. Kilp sur l'impact de l'Eglise sur le développement des clivages politiques dans sept pays.

5 En tout cas, un livre fort utile, qui offre à la fois une information dense et suscite la réflexion pour le géographe politique. 